\title{
Gas transport in granular compacted bentonite: coupled hydro- mechanical interactions and microstructural features
}

\author{
Laura Gonzalez-Blanco ${ }^{1 *}$, Enrique Romero ${ }^{2}$, and Paul Marschall ${ }^{3}$ \\ ${ }^{1}$ Geomechanics Group, International Center for Numerical Methods in Engineering, Gran Capità s/n 08034, Barcelona, Spain \\ ${ }^{2}$ Department of Civil and Environmental Engineering, Universitat Politècnica de Catalunya, Jordi Girona 1-3, 08034, Barcelona, Spain \\ ${ }^{3}$ Nationale Genossenschaft für die Lagerung radioaktiver Abfälle (NAGRA), Wettingen, Switzerland
}

\begin{abstract}
The initial conditions (dry density and saturation state), the stress state and its history, and the deformation undergone during gas migration, affect the gas transport processes in granular compacted bentonite. Additionally, the sample microstructure set on compaction has a significant influence since gas tends to flow through preferential pathways. This experimental study intends to shed light on the gas transport and their coupled hydro-mechanical interactions with particular emphasis in the changes of the pore and pathway network. Controlled volume-rate gas injection followed by shut-off and dissipation stages have been performed under oedometer conditions. The microstructure of the samples has been characterised with three different techniques before and after the gas injection tests: Mercury Intrusion Porosimetry (MIP), Field-Emission Scanning Electron Microscopy (FESEM) and X-ray Micro-Computed Tomography $(\mu-\mathrm{CT})$. The results show a coupling of the deformational behaviour during the gas flow, revealing an expansion of the samples upon the development of gas pathways, which have been detected with the microstructural techniques. The opening of these pressure-dependent and connected pathways plays a major role in gas migration.
\end{abstract}

\section{Introduction}

The gas transport process in granular compacted bentonite is affected by several factors, such as the dry density, the pore size distribution and their connectivity, the heterogeneous distribution of porosity, the saturation state, the stress state and its history, the deformation undergone during gas injection and dissipation, and the gas injection regime [1-5]. Therefore, an extensive experimental program has been performed on granular compacted MX-80 bentonite to study the influence of some of these aspects on gas migration. An oedometer cell has been selected to perform the gas migration experiments on samples after being subjected to a saturation process. Gas was injected using controlled volume-rate followed by a shut-off and a dissipation stage at constant vertical stress. The tests served to identify the coupling between the hydraulics and the mechanics during this process by capturing the volume change response to gas injection. Additionally, the pore and pathway network has been characterised at the initial stage and after gas migration using three different techniques: Mercury Intrusion Porosimetry (MIP) and Field-Emission Scanning Electron Microscopy (FESEM) and X-Ray Micro-Computed Tomography $(\mu-C T)$ [6]. Results have allowed detecting preferential pathways after gas injection/dissipation tests.

Corresponding author: laura.gonzalez.blanco@upc.edu

\section{Materials and methods}

\subsection{Material}

The material used in this study is granular Na-bentonite MX-80, which presents large-size particles (around 50\% larger than $2 \mathrm{~mm}$ ). The main properties of the bentonite are summarised in Table 1.

Table 1. Main properties of the MX-80 granular bentonite.

\begin{tabular}{l|l}
\hline \multicolumn{2}{l}{ Properties } \\
\hline Density solids / density water, $\rho_{s} / \rho_{w}$ & 2.80 \\
Liquid limit, $w_{L}$ & $420^{+}$to $575^{*} \%$ \\
Plastic limit, $w_{P}$ & $53^{*}$ to $65^{+} \%$ \\
Montmorillonite content & 89 to $90 \%$ \\
Hygroscopic water content, $w_{h}$ & $7.2 \%$ \\
Total suction, $\psi$ & $100 \mathrm{MPa}$ \\
Total specific surface area, $S_{s}$ & $523^{+} \mathrm{m}^{2} / \mathrm{g}$ \\
\hline+
\end{tabular}

${ }^{+}[3] ;{ }^{*}[7]$

\subsection{Sample preparation paths}

Samples were compacted to reach an initial dry density of $1.55 \mathrm{Mg} / \mathrm{m}^{3}$ at the dry side of the optimum using an initial water content of $20 \%$. In this way, the bentonite 
presents an aggregate-type structure with large-size granules typical of compacted samples in the dry zone [8] but with a water content sufficiently high to reduce saturation time.

The stress paths followed to prepare the samples is depicted in the compaction plane (Figure 1a). Bentonite at a hygroscopic water content (point 0 in Figure 1a at total suction $100 \mathrm{MPa}$ ) was wetted with deionised water to reach a water content around $20 \%$. Equalisation was allowed during a minimum of 48 hours (point 1 in the figure).

The wetted bentonite was statically compacted under oedometer conditions at a constant vertical displacement rate of $1 \mathrm{~mm} / \mathrm{min}$ until reaching the dry density of 1.55 $\mathrm{Mg} / \mathrm{m}^{3}$. Vertical stresses and displacements were measured along the compaction (path 1 to 2 in Figure 1a). The maximum vertical stress (compaction stresses) was maintained during 30 minutes before unloading the sample at the same rate (path 2 to $\mathrm{A}$ in the figure). Total suction in the as-compacted state was measured with a dew-point psychrometer under unstressed conditions. Its value is listed in Table 2 together with the main properties representative of the as-compacted state.

Table 2. Main properties at the as-compacted state.

\begin{tabular}{l|l}
\hline \multicolumn{2}{l|}{ Properties } \\
\hline Dry density, $\rho_{d}$ & $1.55 \mathrm{Mg} / \mathrm{m}^{3}$ \\
Water content, $w$ & $20 \%$ \\
Total suction, $\psi$ & $21.1 \mathrm{MPa}$ \\
Vertical compaction stress, $\sigma_{c}$ & 4.9 to $5.1 \mathrm{MPa}$ \\
Void ratio, $e$ & 0.806 \\
Porosity, $\Phi$ & 0.446 \\
Degree of saturation, $S_{r}$ & $69.5 \%$ \\
\hline
\end{tabular}

\subsection{Experimental set-up}

A high-pressure oedometer cell was selected to perform the gas injection tests. The samples, $20 \mathrm{~mm}$ thick and 50 $\mathrm{mm}$ in diameter, were placed between the top and bottom caps made of concentric stainless steel rings with gaps, which operate as coarse porous stones allowing the injection and recovery of water and gas. A vertical hydraulic piston with a maximum capacity of $10 \mathrm{MPa}$ was used to apply the vertical stress. Vertical displacements were measured with an external linear variable differential transformer (LVDT) with a resolution better than $2 \mu \mathrm{m}$ (axial strain resolution below $0.01 \%$ ). Three pressure and volume controllers (PVC) were used to apply fluid pressures on the sample: one for air (injection at upstream point - bottom of the sample ), and two for water (injection at upstream point and recovery at the downstream point). The pressure/volume controllers display a pressure resolution of $1 \mathrm{kPa}$ and volumetric resolution of $1 \mathrm{~mm}^{3}$. A scheme of the set-up of the oedometer cell is presented in Figure 2.
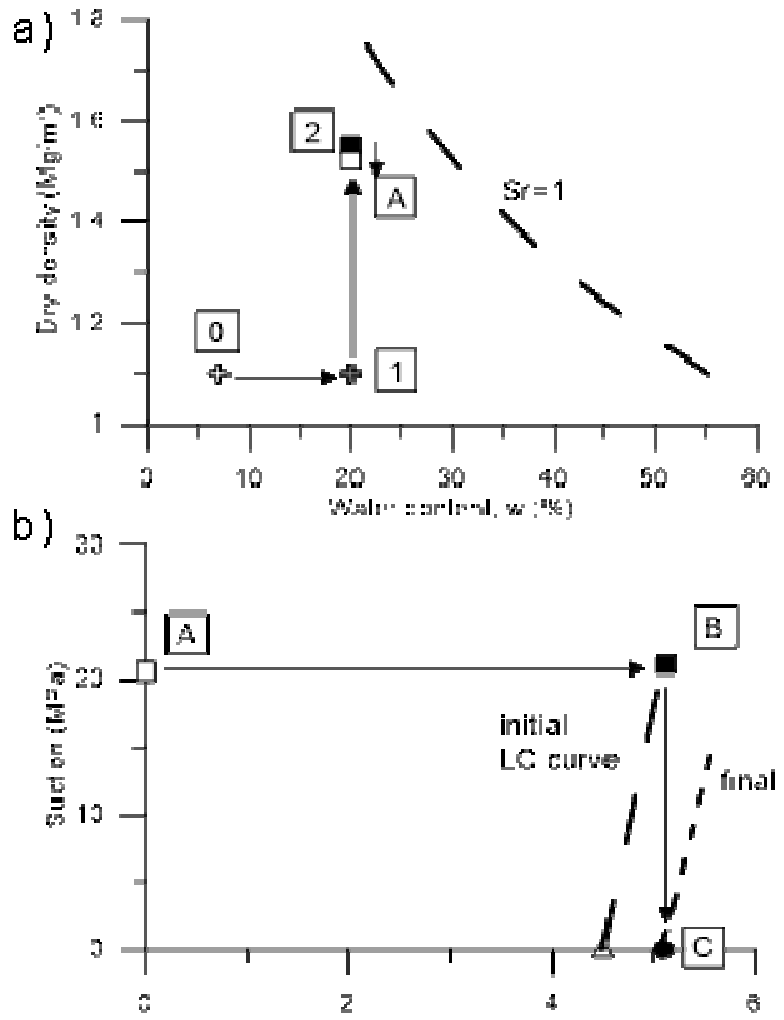

Fig. 1. a) Sample preparation pans to reach a dry density of $1.55 \mathrm{Mg} / \mathrm{m}^{3}$; b) Stress paths followed under oedometer conditions.

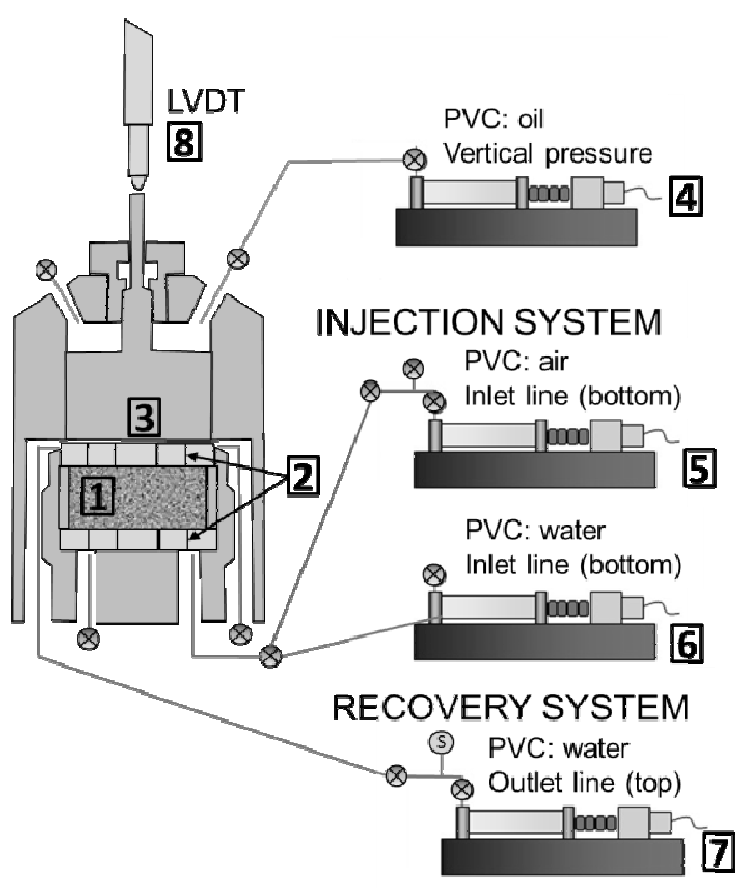

Fig. 2. Scheme of the oedometer set-up: 1) sample; 2) concentric stainless steel rings with gaps; 3 ) axial loading piston; 4) pressure/volume controller (PVC) for vertical stress; 5) PVC for air; 6) and 7) PVCs for water; and 8) LVDT. 


\subsection{Test protocols}

Figure 1b shows the stress paths followed under oedometer conditions. Initially, samples were loaded up to the compaction stress (around $5 \mathrm{MPa}$, see Table 2) at constant water content ( $\mathrm{AB}$ in Figure $1 \mathrm{~b}$ ) assuming that the total suction maintained approximately constant during this process [9]. Path $\mathrm{BC}$ corresponds to the saturation path at constant vertical compaction stress in which samples are placed in contact with deionised water. As observed in the figure, the soaking process induced the dragging of the LC yield locus [10]. Accordingly, some collapse (compressive plastic volumetric strain) occurred during the soaking stage.

In the next stage, water permeability was determined using controlled-gradient at a bottom water pressure of $0.2 \mathrm{MPa}$ and a top pressure of $0.05 \mathrm{MPa}$.

Before the gas injection, water pressure of $0.50 \mathrm{MPa}$ was set (water pressure applied on both bottom and top caps after the water permeability stage). Afterwards, water pressure in the upstream vessel was quickly reduced to atmospheric conditions to allow for its fast replacement by air. Air pressure at the upstream point was rapidly increased from atmospheric conditions to a value of $0.50 \mathrm{MPa}$. Immediately after, air injection was raised from the initial air pressure of $0.50 \mathrm{MPa}$ to the maximum pressure at a constant air volumetric flow rate $(\mathrm{r}=2 \mathrm{~mL} / \mathrm{min})$. This maximum air pressure was limited to $4 \mathrm{MPa}$ to avoid exceeding the minor principal stress. This lateral stress should be close to the vertical stress for approximately the normally consolidated conditions prevailing at the beginning of the injection: $K_{O N C}=1-\sin \phi^{\prime}$ $\approx 0.9$ (for an estimated drained friction angle for MX-80 of $\phi^{\prime}=8^{\circ}$ ). A minimum of $1 \mathrm{MPa}$ can be accepted as the difference between maximum air pressure and vertical stress to avoid preferential air flows between the sample and oedometer ring [11]. The pressure at the downstream vessel was kept at $0.50 \mathrm{MPa}$ during the whole process.

\section{Test results and interpretations}

\subsection{Hydro-mechanical results}

Axial deformations on pre-yield loading to the compaction stresses at constant water content are presented in Figure $3 \mathrm{a}$ for different samples. The deformational response along this stage allows determining the elastic compressibility on loading defined as $\kappa=-\Delta e / \Delta\left(\ln \sigma_{v}\right)$. A value of 0.02 can be estimated at the maximum compressibility zone close to $5 \mathrm{MPa}$.

Figure $3 \mathrm{~b}$ shows the axial strain evolution during the soaking stage (BC in Figure 1b) at constant compaction stress. As observed in the figure, the samples underwent some collapse on wetting, due to the dragging of the LC curve. The measured strains are comparable with the value that can be estimated by the change in the saturated (vertical) yield stress from $\sigma_{\mathrm{v}}{ }^{*}(0)_{\mathrm{i}}=4.5 \mathrm{MPa}$ [1] to $\sigma_{\mathrm{v}}{ }^{*}(0)_{\mathrm{f}}=5.1 \mathrm{MPa}$ as:

$$
\Delta \varepsilon_{v o l}^{p}=\frac{\lambda(0)-\kappa(0)}{1+e} \ln \frac{\sigma_{v}^{*}(0)_{f}}{\sigma_{v}^{*}(0)_{i}}=0.69 \%
$$

in which $\lambda(0)=0.15$ and $\kappa(0)=0.05$ [12], represent the saturated virgin and elastic compressibility parameters.

The saturation was let until deformation stabilisation for periods between 2 and 5 months. The void ratio after soaking was around 0.80 for all the samples.
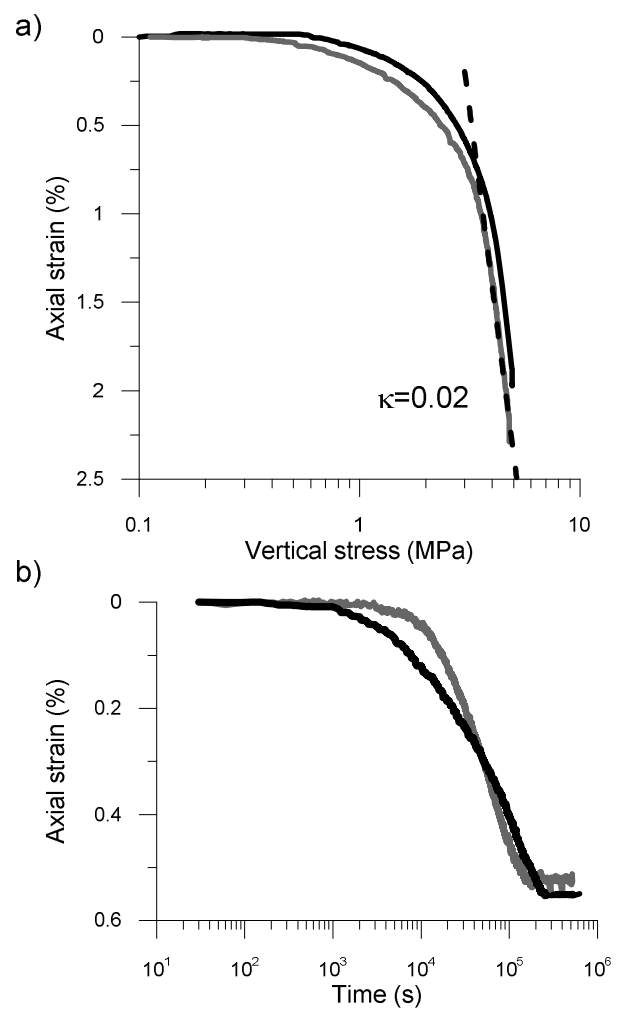

Fig. 3. a) Axial deformation on elastic loading up to the compaction stress at constant water content; b) Collapse during the soaking stage $\mathrm{BC}$ at constant compaction stress.

\subsection{Gas injection results}

Figure 4 shows the results of one selected test in terms of the time evolution of the air injection pressure at the upstream boundary (injection point) and the outflow pressure and volume at the downstream boundary (recovery point), jointly with the average axial strain, calculated based on recorded axial displacements on the top of the sample. The air pressure at the upstream boundary increased in time from 0.5 to $4 \mathrm{MPa}(A$ to $B$ in the figure), followed by shut-off (point $B$ ) and dissipation at closed air injection line $(B$ to $C$ ). The initial injection piston volume including the dead volume of the injection lines was $534 \mathrm{~mL}$ (at $0.50 \mathrm{MPa}$ ). It was re-filled at $250.25 \mathrm{~min}$ - when the air injection pressure reached approximately $2.64 \mathrm{MPa}$ - with $300 \mathrm{~mL}$ of additional volume (measured at atmospheric conditions). The re-filled volume was rapidly increased to $2.64 \mathrm{MPa}$ and then allowed increasing to $4 \mathrm{MPa}$ at the same volumetric rate of $2 \mathrm{~mL} / \mathrm{min}$. The maximum air injection pressure was limited to $4 \mathrm{MPa}$, which was considered higher than the expected air-entry value of the compacted bentonite (around $1 \mathrm{MPa}$ according to results presented in section 3.3). 


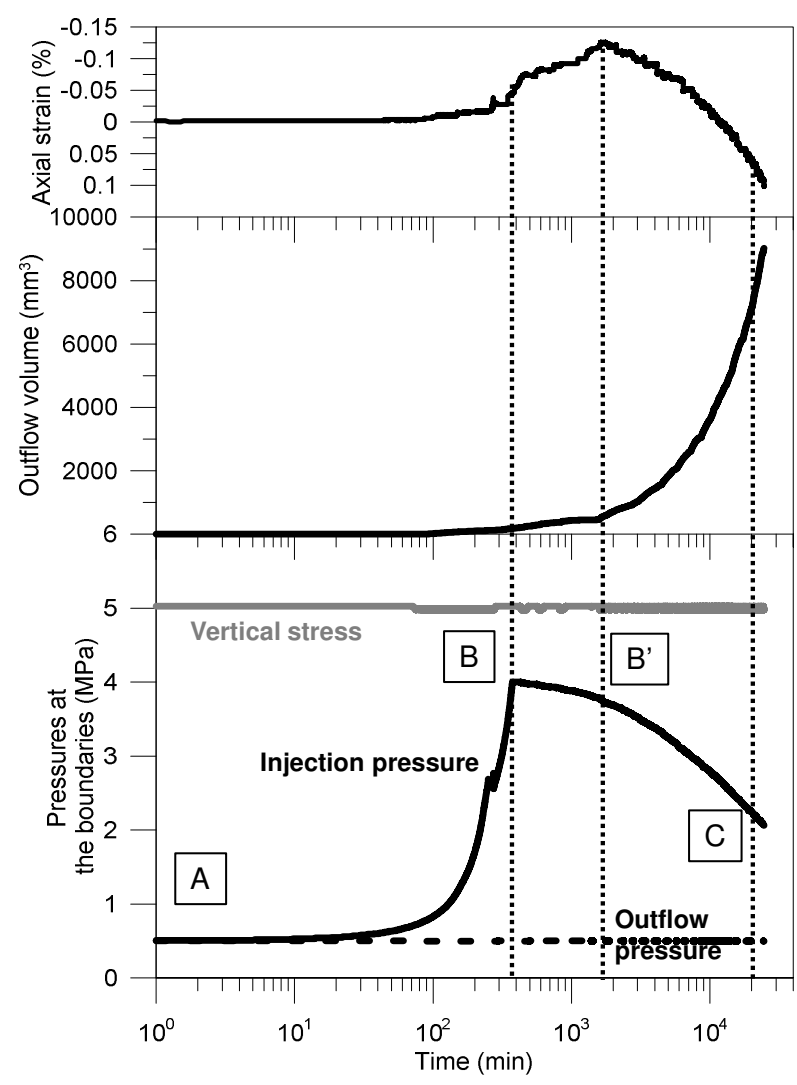

Fig. 4. Time evolution of pressures at the boundaries, outflow volume and axial deformation ( $r=2 \mathrm{~mL} / \mathrm{min})$.

Some outflow was detected at around 100 min when the air pressure was close to $1 \mathrm{MPa}$. After shut-off (point $\mathrm{B}$ in the figure), the outflow volume continued increasing while the sample underwent expansion (negative axial strain). At around $2100 \mathrm{~min}$, the outflow rate speeded up, and the sample started to compress (point $\mathrm{B}^{\prime}$ in the figure) due to the constitutive stress increase at air pressure dissipation.

\subsection{Microstructural analyses}

The microstructure of the samples was analysed at different states with three techniques: Mercury Intrusion Porosimetry (MIP) and Field-Emission Scanning Electron Microscopy (FESEM) and X-Ray MicroComputed Tomography $(\mu-\mathrm{CT})$. The tests were performed on unstressed and freeze-dried samples. Although the freeze-drying process was not needed to $\mu$ $\mathrm{CT}$, it allowed comparing the results between them. It is considered that the unloading stage after the oedometer tests, which was undrained, did not modify the structure of the samples.

Figure 5 shows the pore size distribution functions (PSD) obtained with MIP in terms of the intruded volume of mercury referred to the volume of solids (nonwetting void ratio $e_{n w}$ ) for different entrance pore sizes $x$ [13] of the bentonite in the as-compacted state, after saturation at constant vertical stress and after the air injection test. As observed, the pore network evolved during the different stages. The as-compacted sample presents the expected bimodal distribution of dry-side compaction. During the saturation process, the micropores inside the aggregates, with dominant pore mode at entrance size around $20 \mathrm{~nm}$, did not significantly modify. This fact has also been observed by [14]. On the other hand, the pores at entrance sizes between $100 \mathrm{~nm}$ and $2 \mu \mathrm{m}$ presented at the as-compacted state were clearly reduced. Moreover, some pores larger than $20 \mu \mathrm{m}$ were still present, probably associated with some pore volume between large saturated granules. Even though the saturation period was large, it is possible that the microstructure could evolve for longer periods as indicated in [14] where the authors noticed changes with time until 90 days. The air-entry value, cited in section 3.2, was estimated from the dominant pore mode according to the Young-Laplace equation on the saturated bentonite, given a value around $1 \mathrm{MPa}$.

Post-mortem samples after saturation and after air injection presented the same pore mode at the microscale (around $20 \mathrm{~nm}$ ), whereas the detected porosity between $100 \mathrm{~nm}$ and $3 \mu \mathrm{m}$ practically disappeared. In contrast, pores at entrance sizes larger than $20 \mu \mathrm{m}$ were more developed after the injection, which could reveal the opening of preferential pathways between large saturated granules.

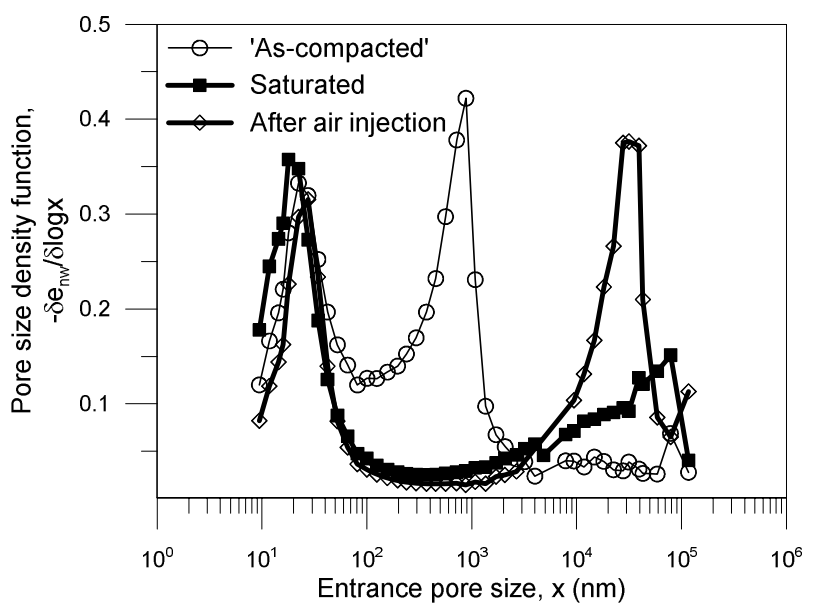

Fig. 5. PSD functions of samples in 'as-compacted' state, after saturation and after air injection.

The opening of preferential paths suggested by MIP results was also observed with FESEM and $\mu$-CT techniques performed after a fast water undrained path.

As observed in the electron microscope images in Figure 6, after the air injection test, the sample presented some fissures, which were not noticeable after saturation.

$\mu$-CT with a voxel resolution of $20 \mu \mathrm{m}$ were performed in three samples at different states: ascompacted, saturated and after gas injection, and the images were analysed with the software ImageJ [15]. Again, fissures after gas migration were clearly visible (Figure 7). The opening of these preferential pathways for air passage might have an important influence on the intrinsic permeability of the compacted bentonite [16]. For that reason, the volume of fissures/pathways was quantified following the methodology presented in [17] (multiscale Hessian fracture filtering). The quantitative analysis of the fissures $(x>20 \mu \mathrm{m})$ obtained after the 
filtering process of the $\mu$-CT images resulted in a fissured volume of $172 \mathrm{~mm}^{3}$, which represents the $11 \%$ of the total volume.

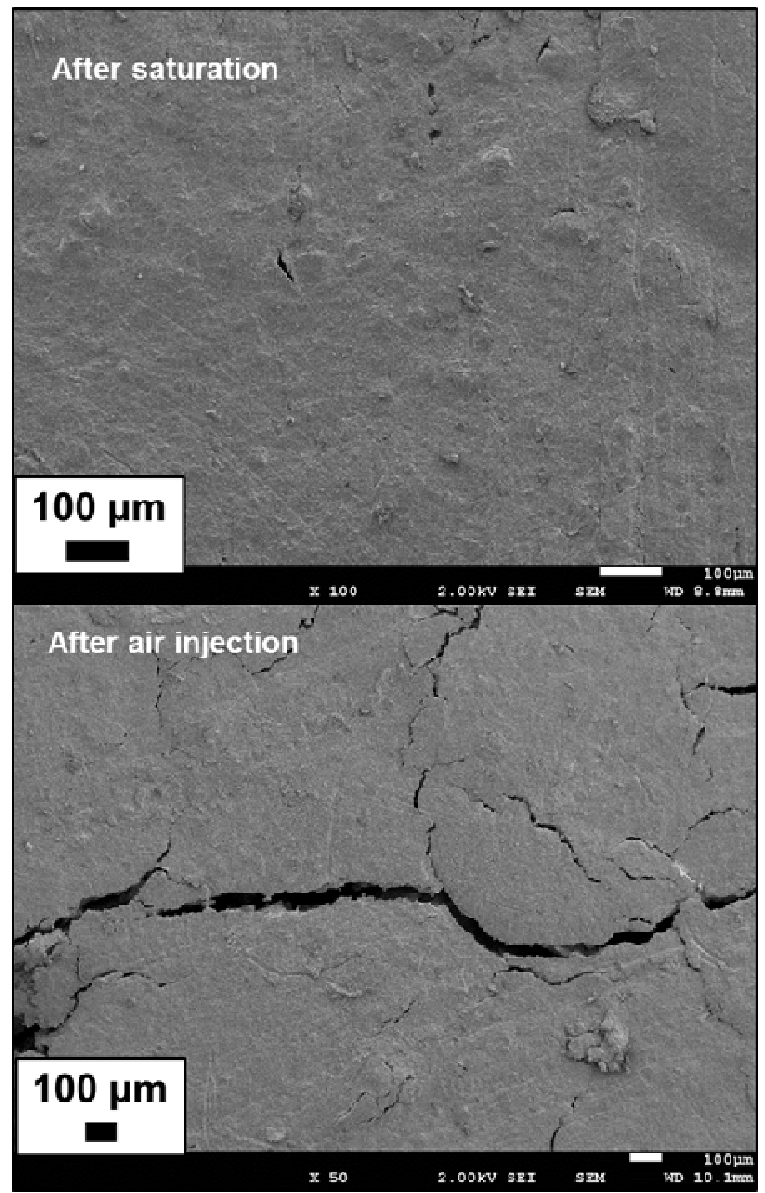

Fig. 6. FESEM images of samples after saturation (top) and after air injection (bottom).

Additionally, data from MIP were analysed by using a fissured void ratio $\left(e_{\text {fissured }}\right.$, defined as the area below the pore size density function after the air test at pore sizes larger than $20 \mu \mathrm{m}$ [18] and serve to quantify the volume of fissures respect to the volume of solids induced by air migration. This fissured void ratio was normalised with respect to the total void ratio $e=0.80$ $\left(e_{\text {fissured }} / e\right)$. It is, therefore, possible to establish a comparison between the results from these two techniques. The comparison of the fissured void ratio obtained with both techniques (Table 3) shows an encouraging agreement.

Table 3. Fissured void ratio quantified with MIP and $\mu$-CT.

\begin{tabular}{c|c|c}
\hline Technique & $\mathbf{e}_{\text {fissured }}$ & $\mathbf{e}_{\text {fissured }} / \mathbf{e}$ \\
\hline MIP & 0.23 & 0.28 \\
\hline$\mu-C T$ & 0.20 & 0.26 \\
\hline
\end{tabular}

The normalised fissured void ratio was also useful to provide information on the expected value of the final degree of saturation of the bentonite after the air injection test. Assuming that all fissures were desaturated, and in the clay matrix the pores were still saturated, then the degree of saturation was defined as $S_{r}$ $=1-e_{\text {fissured }} / e$. Final $S_{r}$ between 0.720 .74 could be estimated from MIP and $\mu$-CT results when all fissures larger $20 \mu \mathrm{m}$ were desaturated.

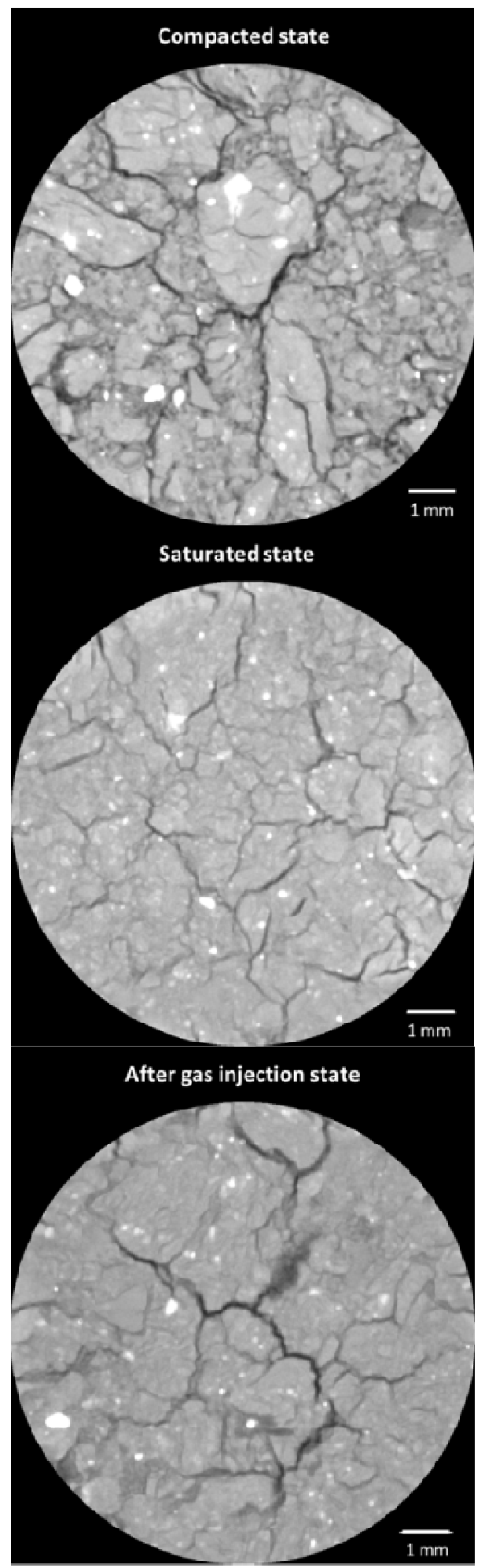

Fig. 7. $\mu$-CT images of bentonite samples at the as-compacted (top) saturation state (middle) and after air migration (bottom).

\section{Concluding remarks}

Experimental work is relevant for understanding the process of gas flow through saturated bentonite 
regarding the safety assessment of the geological disposal for radioactive waste. The test presented corresponded to a series of gas pulse tests (relatively fast air injection tests) designed to investigate the mechanisms of gas flow. The main focus was given to the coupled hydro-mechanical response by measuring sample deformations during the air injection and dissipation stages.

The air injection tests were performed in an oedometer cell on previously saturated samples. Large amounts of fluid volume (mainly air) were measured at the downstream reservoir coupled with expansive deformation, which indicated the break-through point was exceeded.

MIP tests allowed detecting a new family of large pores with entrance sizes larger than $20 \mu \mathrm{m}$ after the air injection tests, which suggested the development of preferential paths during the air injection experiments. FESEM and $\mu$-CT images in post-mortem samples confirmed the opening of fissures or pathways due to gas passage.

Image analyses through multiscale Hessian fracture filtering allowed the quantification of the volume of fissures after the air tests. To obtain comparable results with MIP technique, only fissures larger than $20 \mu \mathrm{m}$ ( $\mu$ CT voxel resolution) were considered. The volume of fissures respect to the volume of solids (fissured void ratio) was 0.19 and 0.20 for MIP and $\mu \mathrm{CT}$, respectively. This information was used to estimate the final value of the degree of saturation after the air injection assuming that all the fissures larger than $20 \mu \mathrm{m}$ were desaturated.

In a step forward, a connectivity filtering analysis of the $\mu$-CT images will help to assess better the pathways followed by the gas passage.

\section{Acknowledgements}

The authors acknowledge the financial support of the 'Nationale Genossenschaft für die Lagerung radioaktiver Abfälle' NAGRA (Switzerland) through different research projects with the 'International Center for Numerical Methods in Engineering' CIMNE (Spain) and linked to the 'Task Force on Engineered Barrier Systems - THM Session - Gas transport in bentonite' (2016-2019).

\section{References}

1. M. V. Villar, Informes Técnicos Ciemat 1053. 2005, 39.

2. S. Tripathy, A. Sridharan, T. Schanz, Canadian Geotechnical Journal. 2004, 41 (3), 437-450. DOI: 10.1139/t03-096.

3. A. Seiphoori, A. Ferrari, L. Laloui, Géotechnique. 2014, 64 (9), 721-734. DOI: 10.1680/geot.14.P.017.

4. E. Romero, L. Gonzalez-Blanco, NAGRA Technical Report NAB 17-09. 2017, 62.

5. L.-Y. Cui, W.-M. Ye, Q. Wang, Y.-G. Chen, B. Chen, Y.-J. Cui, Journal of Materials in Civil Engineering. 2020, 32 (7), 04020190. DOI: 10.1061/(ASCE)MT.1943-5533.0003206.
6. L. Gonzalez-Blanco, E. Romero, C. Jommi, X. Sillen, X. Li, in Advances in Laboratory Testing and Modelling of Soils and Shales (ATMSS) (Eds: A. Ferrari, L. Laloui), Springer International Publishing, Cham 2017.

7. Q. Wang, A. M. Tang, Y. J. Cui, P. Delage, J. D. Barnichon, W. M. Ye, Soils and Foundations. 2013, 53 (2), 232-245. DOI: 10.1016/j.sandf.2013.02.004.

8. G. Musso, E. Romero, G. Della Vecchia, Géotechnique. 2013, 63 (3), 206-220. DOI: 10.1680/geot.SIP13.P.011.

9. E. Romero, a. Gens, a. Lloret, Engineering Geology. 1999, 54, 117-127. DOI: 10.1016/S00137952(99)00067-8.

10. E. E. Alonso, A. Gens, A. Josa, Géotechnique. 1990, 40 (3), 405-430.

11. L. Gonzalez-Blanco, E. Romero, C. Jommi, X. Li, $X$. Sillen, Geomechanics for Energy and the Environment. 2016, 6, 81-100. DOI: 10.1016/j.gete.2016.04.002.

12. V. Navarro, L. Asensio, Á. Yustres, G. De la Morena, X. Pintado, Engineering Geology. 2016, 202 (March), 99-113. DOI: 10.1016/j.enggeo.2016.01.005.

13. E. Romero, P. H. Simms, Geotechnical and Geological Engineering. 2008, 26, 705-727. DOI: 10.1007/s10706-008-9204-5.

14. P. Delage, D. Marcial, Y. J. Cui, X. Ruiz, Géotechnique. 2006, 56 (5), 291-304. DOI: 10.1680/geot.2006.56.5.291.

15. C. A. Schneider, W. S. Rasband, K. W. Eliceiri, Nature Methods. 2012, 9 (7), 671-675. DOI: 10.1038/nmeth.2089.

16. L. Gonzalez-Blanco, E. Romero, P. Marschall, Proc. of International Symposium on Energy Geotechnics, September 25-28 Lausanne, Switzerland. 2018.

17. M. Voorn, U. Exner, A. Rath, Computers and Geosciences. 2013, 57, 44-53. DOI: 10.1016/j.cageo.2013.03.006.

18. L. Gonzalez-Blanco, E. Romero, Géotechnique. Submitted revised version 